Scientia studia, São Paulo, v. 11, n. 3, p. 613-35, 2013

\title{
îे \\ Desacordo racional e controvérsia científica
}

\author{
Alexandre Luis Junges
}

\begin{abstract}
曲
RESUMO

O debate epistemológico ocorrido recentemente sobre o que veio a ser chamado de "o problema do desacordo racional" retomou a discussão, presente no ceticismo antigo, relativa ao significado epistêmico do desacordo. Similar ao cético pirrônico, alguns autores envolvidos no debate contemporâneo argumentaram que em contextos controversos, onde há desacordo sobre alguma questão específica, a atitude racional de ambos os lados do debate é a suspensão do juízo. Para esses autores, tal veredito deve ser estendido a diversas áreas do conhecimento humano, resultando num ceticismo local relativo a tópicos controversos. Este artigo trata dessa problemática no campo científico. Em diversos episódios de controvérsia científica, cientistas exibem desacordos persistentes em que cada lado do debate mantém sua posição em face do desacordo. Nesse contexto, coloca-se a pergunta pela possibilidade do desacordo racional entre cientistas considerados pares epistêmicos. A partir da característica estrutural e dinâmica da ciência, argumenta-se que o desacordo racional entre cientistas é possível. Ou seja, diferente do que sustentam autores contemporâneos, no contexto científico o significado epistêmico do desacordo não é, necessariamente, o agnosticismo.
\end{abstract}

Palavras-chave • Controvérsia. Desacordo. Evidência. Ceticismo. Racionalidade. Justificação. Par epistêmico.

\section{Desagordo e Gontrovérsia Gientífica}

Desacordos são abundantes: seja na filosofia, na política, na moral, na religião e mesmo na ciência encontramos casos atuais ou passados de desacordo sobre alguma matéria em discussão. Alguns desses desacordos são superficiais, facilmente resolvidos, outros mais profundos podem resultar em controvérsias que se estendem por muitos anos até que uma resolução racional seja possível e um novo consenso alcançado. Embora muitas vezes o desacordo se deva à ação de fatores sociais e motivacionais como ideologia, pressões institucionais, desejo de fama, orgulho, preconceito e rivalidade, controvérsias persistentes parecem sugerir que há também desacordos que repousam em razões que podemos chamar de epistêmicas.

De fato, a existência de desacordos persistentes, onde cada lado do debate persiste em sua posição, suscita uma antiga questão filosófica relativa ao status epistêmico das crenças dos agentes envolvidos no desacordo. Recentemente, epistemólogos contem- 
porâneos se ocuparam exclusivamente dessa questão. O problema do desacordo racional, como ficou conhecido, retoma numa nova roupagem discussões relativas ao modo do desacordo, que, desde os tempos do ceticismo pirrônico, tem-se demonstrado um genuíno problema filosófico (cf. Lammenranta, 2011). Diversos autores envolvidos no debate contemporâneo defenderam uma conclusão cética similar àquela presente no ceticismo pirrônico antigo. Especialmente, Richard Feldman defendeu que o desacordo entre pares pode forçar um tipo peculiar de ceticismo, um ceticismo local relativo a determinados tópicos controversos (cf. Feldman, 2006, 2007). Ele escreve para que se

\begin{abstract}
(...) considere aqueles casos em que a coisa razoável a pensar é de que outra pessoa, tão sensata, séria e cuidadosa como nós mesmos, tenha revisto as mesmas informações que nós e tenha chegado a uma conclusão contrária a nossa (...). Uma descrição honesta da situação reconhece a sua simetria (....). Nesses casos eu penso que a conclusão cética é a razoável: não é o caso de que ambos os pontos de vista são razoáveis, e não é o caso de que nosso próprio ponto de vista é de alguma forma privilegiado. Antes, a suspensão de juízo é o recomendado (Feldman, 2006, p. 235).
\end{abstract}

A posição de Feldman rapidamente formou adeptos, inaugurando o que veio a ser conhecido como a posição conformista sobre o desacordo (cf. também Christensen, 2007; 2011 e Elga, 2007). Essa posição, na versão inicialmente defendida por Feldman, pode ser expressa num princípio geral nos seguintes termos: Se S crê justificadamente que P num instante imediatamente anterior a te $S$ descobre em t que um par epistêmico com respeito a $P$, que compartilha a evidência de Spara $P$, descrê que $P$, então Snão está justificado em crer que P em $t$ (cf. Feldman, 2009, p. 295). Esta maneira de ver a questão apresenta semelhanças com o modo do desacordo presente no ceticismo pirrônico, pois de acordo com o argumento pirrônico, se existe um desacordo insolúvel sobre P, então devemos suspender o juízo sobre $P$.

Contudo, algumas particularidades da argumentação contemporânea devem ser mencionadas, em especial, no que concerne às condições de paridade epistêmica e igualdade evidencial que devem ser satisfeitas. Relativo à primeira condição, conformistas consideram que o desacordo ocorre entre pares epistêmicos. Ou seja, indivíduos aproximadamente iguais com respeito a inteligência, capacidade de raciocínio e domínio do assunto em questão. Por sua vez a segunda condição requer que os pares estejam considerando a mesma evidência (ou aproximadamente a mesma evidência), ou seja, ambos tiveram acesso aos dados e informações relevantes sobre a questão em disputa.

Nesse sentido, autores conformistas têm chamado a atenção para a simetria existente na situação de desacordo. Para tais autores, em face dessa simetria - pares igual- 
mente competentes que avaliaram a mesma evidência - uma explicação do desacordo que sugira que meu par está em erro não é mais razoável do que a explicação que sugere que eu estou em erro (cf. Christensen, 2007, p. 198). Desse modo, a opção racional é revisar consideravelmente a nossa posição e, em alguns casos, suspender o juízo se quisermos evitar a acusação de dogmatismo ou irracionalidade.

De fato, o apelo intuitivo dessa posição é inegável. Como destaca Christensen, todos nós vivemos num estado de imperfeição epistêmica, seja porque a evidência que possuímos é limitada, ou porque nossas avaliações da evidência são imperfeitas. Ao mesmo tempo, todos nós somos confrontados a cada dia com situações em que existe a possibilidade de melhora epistêmica (epistemic improvement), seja pela aquisição de novas evidências, ou identificando erros na avaliação evidencial (cf. Christensen, 2007, p. 187). Desse modo, da perspectiva conformista desse autor, o desacordo representa boas notícias (good news), pois representa justamente uma dessas possibilidades de melhora epistêmica. Ou seja, a existência de um par epistêmico em desacordo me fornece razões para suspeitar de possíveis erros que eu possa ter cometido e, desse modo, me levar a eliminar tais erros. Dentro desse quadro, até mesmo a suspensão de juízo pode representar uma melhora epistêmica, na medida em que evita a manutenção de crenças que são o resultado de erros de avaliação evidencial.

Contudo, embora inicialmente atraente, essa posição pode ter consequências dramáticas para a racionalidade dos agentes que mantêm sua posição em face do desacordo. De fato, as consequências dessa posição são embaraçosas quando consideramos o tópico das controvérsias científicas. Atualmente é amplamente reconhecido que episódios de controvérsia façam parte de importantes avanços na ciência. Um olhar para a história da ciência revela que grandes conquistas científicas, como o modelo heliocêntrico de Copérnico, a teoria da relatividade, a teoria quântica, a teoria da evolução etc., envolveram, em alguma medida, uma disputa ou desacordo entre cientistas. Durante tais períodos de controvérsia científica, cientistas exibiram um desacordo persistente sobre determinada questão em disputa.

De fato, como foi observado por Ernan Mcmullin, uma controvérsia científica “[é] uma disputa pública e persistentemente mantida. Uma controvérsia científica se ocupa com uma questão de crença. Cada lado argumenta que o outro está errado e que eles mesmos estão certos ou, pelo menos, têm o melhor caso" (cf. Mcmullin, 1987, p. 51). 'Assim, pode-se dizer que durante períodos de controvérsia científica há desacordos momentaneamente insolúveis entre cientistas, onde cada lado do debate man-

1 Importante lembrar que, para Mcmullin, não é qualquer desacordo que resulta numa controvérsia científica. Uma controvérsia científica existe somente se partes substanciais da comunidade científica reconhecem que há algum mérito em ambos os lados de um desacordo público (cf. Mcmullin, 1987, p. $5^{3}$ ). 
tém sua posição em face do desacordo com os seus colegas pares. Seria, contudo, apropriado dizer que os cientistas engajados numa controvérsia estão sendo irracionais ao defenderem e manterem sua posição?

Vale notar que, em boa medida, é justamente por causa dessa suspeita de irracionalidade dos protagonistas envolvidos que o tópico das controvérsias científicas recebeu pouca atenção por parte de filósofos da ciência da tradição clássica. ${ }^{2}$ De acordo com essa tradição a evidência funcionaria como um árbitro neutro que permite decidir qualquer disputa, desde que suficiente tempo e pesquisa fossem despendidos. Assim, um desacordo duradouro entre dois cientistas é sinal de que a manutenção do desacordo se deve à influência de fatores não epistêmicos ou extracientíficos. Além disso, essa aversão às controvérsias está em consonância com o fato de que, em grande medida, o tópico das controvérsias científicas tem sido o lugar preferido de abordagens sociológicas da ciência. Essas abordagens visam identificar a influência de elementos psicossociais na ciência e, assim, extrair conclusões sobre a influência desses elementos no desenvolvimento do conhecimento científico (cf. Mcmullin, 1984; Brown, 2001). Novamente aqui, ambas as abordagens têm consequências dramáticas para a racionalidade individual dos cientistas em desacordo, já que, para tais concepções, a manutenção do desacordo se deve a fatores não epistêmicos. ${ }^{3}$

Contudo, muito mudou na filosofia da ciência a partir da metade do século passado, colocando em questão a concepção clássica do método científico. Sabe-se hoje que os fatos envolvem interpretação, que a relação entre evidência e hipótese resiste a uma análise lógica, que a evidência subdetermina a hipótese e que outros elementos são necessários para preencher a lacuna. Trabalhos importantes como de Thomas Kuhn demonstraram que juízos de valor fazem parte da escolha de teorias, e que aquilo que cientistas compartilham não é suficiente para ditar uma escolha unívoca (cf. Kuhn, 1977). Esse cenário permite compreender que abordagens mais permissivas da racionalidade, do que aquelas presentes na tradição clássica, são possíveis e que o desacordo não precisa necessariamente repousar em causas que remontam a fatores extracientíficos ou não epistêmicos. Como escreve Mcmullin: “(...) uma vez que é reconhecido que a avaliação teórica é uma forma complexa de juízo de valor, a persis-

\footnotetext{
2 Ou seja, aquela tradição que vai desde Aristóteles, passando por Descartes, Kant e o positivismo lógico, e que compartilha duas teses: fundacionismo (ou seja, a ideia de que a ciência deve possuir um fundamento composto por uma classe especial de proposições verdadeiras) e logicismo (a ideia de que a ciência possui um método que permite decidir em cada caso qual de duas teorias é a melhor) (cf. Mcmullin, 1987, p. 50).

3 Entenda-se por "não epistêmicos" fatores como: personalidade (abertura à crítica, ambição etc.) do cientista, pressões institucionais, opção ideológica, influências políticas (financiamento), hostilidade entre cientistas, entre outros. Tais fatores contrastam com os "fatores epistêmicos" entre os quais podemos citar: resultados observacionais e experimentais, teorias aceitas, acusações de inconsistência, resultados teóricos, interpretações, pressuposições, críticas e respostas (cf. Mcmullin, 1987, p. 59).
} 
tência de teorias competidoras se segue imediatamente como uma consequência" (Mcmullin, 1982, p. 17).

Da mesma forma, no que concerne ao tópico das controvérsias científicas, surgiram nos últimos anos publicações importantes para preencher a lacuna deixada pela tradição clássica, tornando o tópico das controvérsias um assunto de ocupação também do filósofo (cf. Engelhardt \& Caplan, 1987; Machamer et al., 2000). Se por um lado as discussões apresentadas por esses autores revelam a dificuldade que se coloca quando tomamos a tarefa de fazer uma análise satisfatória dos fatores envolvidos numa controvérsia, para tais autores, longe de ser sinal de irracionalidade por parte dos cientistas, a controvérsia é parte constitutiva da ciência e, em boa medida, o lugar natural do criticismo científico.

Neste ensaio, no espírito dessas abordagens mais permissivas da racionalidade, pretende-se apresentar uma defesa do desacordo racional na ciência. Ou seja, contrário ao que recomenda a posição conformista, cientistas que mantêm sua posição em face do desacordo não estão sendo, necessariamente, irracionais. Nesse sentido, um primeiro passo em direção à possibilidade do desacordo racional na ciência é estabelecer a existência de desacordos entre cientistas que não remontam a fatores não epistêmicos. Ou seja, devemos nos perguntar se as razões que levam ambos os lados da disputa a defender sua teoria são razões epistêmicas, e se uma explicação da controvérsia em termos epistêmicos é concebível.

Defenderemos que tal explicação é possível observando a natureza de larga escala da ciência e consequentemente as diferentes vias de acesso que os cientistas têm a determinada hipótese. Neste intuito, tomaremos como exemplo um caso histórico de controvérsia científica, a saber, a controvérsia da deriva continental. Após uma exposição do debate da controvérsia da deriva continental nos serviremos das análises de autores como Andrew Lugg, Miriam Solomon e Naomi Oreskes que, de diferentes maneiras, enfatizaram o papel da perspectiva de acesso dos cientistas ao sistema de conhecimento científico para explicar o desacordo entre eles. De fato, tal abordagem permite tornar plausível a existência do desacordo entre cientistas sem remeter a fatores não epistêmicos, mesmo quando tais cientistas analisam os mesmos dados ou evidências.

Por fim, confrontaremos diretamente a problemática contemporânea do desacordo entre pares, ou seja, a questão relativa à possibilidade de um cientista manter sua posição quando fica sabendo da existência de um par epistêmico que discorda da sua posição. Embora a posição conformista possua considerável plausibilidade, na medida em que visa evitar casos flagrantes de resistência que beiram o dogmatismo, argumentaremos que é possível evitar casos de dogmatismo e, consequentemente, manter uma atitude de tolerância frente a concepções rivais sem adotar uma norma geral que 
dita o agnosticismo para todos os casos de desacordo. Nesse sentido, enfatizaremos o aspecto dinâmico das controvérsias científicas para argumentar que o significado epistêmico do desacordo não é, necessariamente, o agnosticismo.

\section{UM CASO HISTÓRICO: 0 DEBATE ACERCA DA DERIVA CONTINENTAL}

Este debate ocorreu no campo da geologia, após Alfred Wegener apresentar pela primeira vez a sua defesa da teoria da deriva continental, que fora publicada num artigo em 1912 e consequentemente em seu livro The origin of continents and oceans (1915). Neste último, Wegener apresentou uma teoria extensa que rivalizava com as explicações predominantes de fenômenos geológicos visíveis como, por exemplo, as cadeias montanhosas e a configuração dos continentes e oceanos. Wegener, inicialmente impressionado pela complementaridade das costas marítimas da América do Sul e da África, buscou desenvolver a ideia, já mencionada por outros autores, de que num tempo remoto os continentes estavam unidos formando um único continente gigante que Wegener passou a denominar de Pangea. Considerou, então, que forças de origem gravitacional exercidas pelo Sol e pela Lua, bem como forças decorrentes da rotação da Terra, geraram a separação dos continentes que, de modo análogo ao movimento de icebergs, começaram a se movimentar horizontalmente sobre o leito oceânico afastando-se uns dos outros. Os continentes constituídos de material mais leve denominado sial (minerais de sílica e alumínio) seriam capazes de flutuar sobre o material mais denso denominado sima (minerais de sílica e magnésio) que constitui o assoalho oceânico (cf. Frankel, 1987, p. 204; Leinz \& Amaral, 2001, p. 381).

Segundo Frankel, Wegener argumentou que sua teoria oferecia soluções para alguns dos principais problemas empíricos no campo da geologia da época, entre eles (cf. Frankel, 1987, p. 205):

(a) Por que existe uma complementaridade continental entre a África e a América do Sul?

(b) Por que há tantas similaridades geológicas entre a África e a América do Sul?

(c) Por que há tantas similaridades passadas e atuais entre as formas de vida da África e da América do Sul?

(d) Por que a localização das cadeias de montanhas é usualmente ao longo das costas? 
Se considerarmos o conjunto (a)-(d) como constituindo um conjunto inicial de parte considerável da evidência envolvida no debate, podemos agora observar de que modo os lados da disputa buscavam explicações e acomodações de suas teorias a esses e outros fenômenos. Vejamos como a dinâmica do debate evoluiu. ${ }^{4}$

Com base no sucesso em explicar esses fenômenos, Wegener procurou criticar as teorias fixistas predominantes na época, considerando que sua explicação era superior. Uma dessas teorias era a teoria da contração. Essa teoria dizia que o interior do globo terrestre está contraindo desde os primórdios devido à perda térmica constante. Assim, a crosta terrestre estaria afundando em direção ao núcleo o que produziria um efeito de cunha, gerando forças tangenciais que, forçando para os lados, explicariam a formação de montanhas e mesmo a formação de oceanos. A outra teoria fixista da época era a teoria permanentista. Ela considerava que os continentes e oceanos não haviam sofrido alterações de posição e configuração desde a sua formação. 5

Para dar conta de evidências como a de (c), fixistas (contracionistas) postularam que em tempos remotos haveria pontes de terra (land-bridgers) entre os continentes que possibilitavam a migração das espécies de um continente para o outro. A dificuldade, apontada por críticos como Wegener, era a de que não havia mecanismos conhecidos que explicassem o afundamento e desaparecimento dessas pontes de terra no oceano, sendo assim, muito improvável que tivessem existido. Além disso, a teoria contracionista estava em conflito com novos resultados de estudos geodésicos como o estabelecimento do princípio da isostasia que era irreconciliável com a ideia de que os continentes pudessem afundar transformando-se em oceanos (cf. Oreskes, 1999, p.47). De fato, fixistas (permanentistas), que concordavam com a crítica de Wegener contra a possibilidade do desaparecimento das pontes de terra, propuseram uma explicação em termos de pontes de terra existentes, como o canal do Panamá e o estreito de Bering, em conjunto com mudanças no nível dos oceanos. Contudo, para Wegener, os permanentistas não dispunham de uma explicação satisfatória, não sendo capazes de explicar a grande variedade de similaridades de formas de vida (cf. Frankel, 1987, p. 207). Desse modo, Wegener considerava sua solução superior à solução dos fixistas.

Por sua vez, os fixistas dirigiram diversas críticas ao modelo de Wegener. A partir da década de 1920 uma das objeções preferidas de geofísicos, da corrente permanentista americana e de contracionistas como o britânico Harold Jeffreys, dizia respeito à existência de um mecanismo que pudesse explicar a deriva dos continentes. Para geofísicos fixistas o modelo de Wegener era incapaz de fornecer uma explicação

$4 \mathrm{O}$ relato resumido que apresentarei a seguir apresenta apenas alguns episódios que compõem a controvérsia. Para um relato mais completo da controvérsia, ver Frankel (1987) e Oreskes (1999).

5 Para fins de simplicidade, em alguns momentos irei me referir a ambas as teorias opositoras como fixistas, enquanto que, para a teoria da deriva continental, usarei em alguns momentos o termo "mobilista". 
para a existência de forças suficientemente grandes capazes de movimentar os continentes. Se para Wegener tudo se resumiria em encontrar um mecanismo capaz de explicar a existência de tais forças, é interessante observar que para os fixistas isso ainda não bastava. Harold Jeffreys, por exemplo, advertiu que mesmo que existissem tais forças restaria ainda a necessidade de uma explicação sobre como os continentes seriam capazes de sobreviver a tal deslocamento horizontal sem se despedaçarem. Para Jeffreys, era altamente improvável que os continentes pudessem sobreviver a essa jornada (cf. Frankel, 1987, p. 210).

O debate prossegue. Ao final da década de 1920 a reação mobilista é comandada por Arthur Holmes. Embora inicialmente um fixista (contracionista), Holmes fez descobertas importantes sobre quantidades abundantes de radioatividade, o que o levou a considerar improvável a hipótese de que a Terra esteja resfriando e, portanto, tornava implausível a hipótese contracionista de que a crosta terrestre esteja afundando em direção ao núcleo. Mas muito mais que isso, Holmes, que considerava implausível a explicação de Wegener para a deriva, propõe um mecanismo capaz de explicar o movimento dos continentes que será desenvolvido e ampliado por ele durante as décadas de 1930 e 194.0. A ideia proposta por Holmes, que mais tarde deu origem à teoria da expansão dos fundos oceânicos, é que o calor emitido da Terra seria capaz de aquecer o manto de tal forma que este ficasse fluido, permitindo que se formassem correntes de convecção que, desse modo, produziam forças de magnitude suficientemente grande, capazes de deslocar a crosta terrestre que se encontra sobre o manto. Contudo, embora o mecanismo de Holmes representasse um avanço e implementação da teoria de Wegener, fixistas como Jeffreys consideravam que a ideia não era convincente, pois não havia modos de testá-la. $\mathrm{O}$ debate continuou em aberto, e não tardaram a chegar novos argumentos de cada lado do debate.

No início da década de 194. o debate volta a ficar acirrado especialmente quando o paleontólogo fixista americano George Gaylord Simpson, da vertente permanentista, desenvolve uma solução do problema da distribuição das formas de vida envolvendo a especificação de rotas migratórias. Além disso, Simpson dirige forte crítica à interpretação dos fósseis existentes, considerando que seus oponentes haviam sobreestimado consideravelmente o número de casos legítimos que apoiavam sua teoria, seja por terem utilizado critérios taxonômicos incorretos, seja por terem cometido erros de identificação de espécies (cf. Frankel, 1987, p. 218). Alexander du Toit, outro mobilista importante, buscou minimizar a crítica de Simpson argumentando que a distribuição dos mamíferos seria diferente da distribuição de outras formas de vida e teria ocorrido somente após a maior parte do deslocamento dos continentes. Assim, a distribuição dos fósseis de mamíferos ofereceria menos suporte para a deriva continental do que a distribuição de fósseis de outras formas de vida. Contudo, após a crítica 
de Simpson, mesmo Alexander du Toit admitia que havia sobre-estimado a capacidade da deriva continental em explicar a distribuição de todos os tipos de formas de vida. De fato, após a crítica de Simpson, a evidência fóssil, tão enfatizada por Wegener, não podia mais ser utilizada para argumentar apenas em favor da teoria mobilista. Estes agora eram levados a admitir que tal evidência (veja (c) acima) podia ser compatibilizada com a teoria fixista permanentista. Além disso, dada a influência de Simpson na comunidade paleontológica, após a sua crítica produziram-se várias conversões para o lado fixista permanentista do debate (cf. Frankel, 1987, p. 219). Ao que tudo indica, nesse momento, a situação do debate encontrava-se em equilíbrio evidencial. Porém, nenhum dos principais defensores, de ambos os lados da disputa, se sentiu forçado a abandonar a sua crença. Impelidos por seus interesses em defender a sua teoria, cada lado prosseguiu investigando, buscando novas evidências, teorias, hipóteses ou mesmo descortinando falhas na posição adversária.

Segundo Frankel, o prosseguimento do debate é marcado especialmente pelo surgimento de duas novas fontes de dados: as pesquisas em paleomagnetismo e as descobertas em geologia marinha. No início de $195^{\circ}$ os britânicos S. K. Runcorn e P. M. S. Blackett desenvolveram um novo método que permitia determinar a posição prévia de massas de terra em diferentes períodos geológicos (cf. Frankel, 1987, p. 220). A ideia básica era a de que a posição geográfica de uma massa de terra no passado poderia ser determinada se conhecêssemos as antigas direções do magnetismo terrestre, o que poderia ser conseguido pelo estudo de amostras de rochas ricas em minerais magnéticos que armazenavam as impressões do passado. Novamente a balança pende para o lado mobilista, pois, nesse período, uma grande quantidade de dados paleomagnéticos, que apoiavam a teoria mobilista, foram levantados, formando diversos adeptos ao mobilismo. Contudo muitos fixistas não consideraram os dados convincentes. Objetaram que os resultados dependiam de diversas suposições. Por exemplo, que garantia haveria de que as massas de terra não teriam sofrido um movimento de rotação ao invés de deslocamento horizontal? Jeffreys, por sua vez, considerou que os campos magnéticos das amostras poderiam sofrer distorções durante o transporte (cf. Frankel, 1987, p. 223). Outros fixistas simplesmente não deram atenção aos dados que lhes pareciam muito complicados, especialmente entre aqueles geólogos que não possuíam treinamento em geofísica, resultando disso que o debate estava longe de chegar ao término.

Foi no campo da geologia marinha que os avanços finais em direção à resolução da disputa foram feitos. Desta vez, a evidência a favor do mobilismo surge das tentativas de explicar a origem das cristas meso-oceânicas (gigantescas cadeias montanhosas) que se encontram no fundo dos oceanos. Harry Hess, inicialmente um fixista, após propor soluções fixistas que explicassem a origem dessas cristas oceânicas, finalmente, no início da década de 1960, propôs uma solução que implicava em mobilismo. 
Essa teoria, que representou um avanço e implementação da ideias de Holmes, passou a ser conhecida como expansão dos fundos oceânicos (sea floor spreading) (cf. Frankel, 1987, p. 226). A ideia era a de que a expansão ou crescimento do assoalho oceânico se dá devido ao acréscimo de magma. A ascensão do magma produziria um acréscimo do assoalho oceânico que teria como consequência o afastamento dos continentes. A argumentação de Hess se baseou no fato de não existirem rochas mais antigas que 100 milhões de anos nos fundos oceânicos, assim elas teriam sido empurradas para baixo dos continentes. Além disso, a idade dos sedimentos estaria de acordo com o crescimento das placas, sendo que, quanto maior a distância das dorsais mais antigos eram os sedimentos (cf. Leinz \& Amaral, 2001, p. 385). Contudo, conforme nos relata Frankel, houve reações fixistas contra Hess e uma delas foi a de Maurice Ewing que em 1959 propôs uma solução fixista ao problema das dorsais oceânicas.

Finalmente foi a confirmação da hipótese Vine-Matthews-Morley que abriu o caminho para a confirmação da ideia de Hess e, consequentemente, a posterior consolidação da teoria das placas tectônicas. A hipótese Vine-Matthews-Morley dizia que se a hipótese de Hess estivesse correta, então as rochas em torno da crista oceânica deveriam exibir um padrão simétrico de inversão magnética idêntico àquele exibido pelas rochas vulcânicas (cf. Frankel, 1987, p. 229). Novamente os dados paleomagnéticos desempenharam papel importante e em 1966 a hipótese Vine-Matthews-Morley é confirmada pelo trabalho independente de geofísicos, entre eles, os próprios Frederick Vine e Drummond Matthews, e Walter Pitman e J. R. Heitzler (cf. Oreskes, 1999, p. 271). A partir desse momento, embora ainda restassem alguns fixistas remanescentes, como Harold Jeffreys (cf. Oreskes, 1999, p. 86) e o geólogo Russo Beloussov (cf. Lugg, 1978, p. 285), o consenso gradualmente emergente, que culminou com a aceitação da teoria das placas tectônicas, permite considerar que a controvérsia estava encerrada (cf. Frankel, 1987; Oreskes, 1999).

\section{EXPLIGANDO O DESAGORDO NA GONTROVÉRSIA DA DERIVA GONTINENTAL}

Como podemos observar no relato acima, a controvérsia da deriva continental é marcada por um dinamismo que envolve uma considerável distribuição de crenças. Miriam Solomon observa que poucos cientistas engajados no debate adotaram uma atitude de suspensão de juízo (cf. Solomon, 1992, p. 446). Pelo contrário, a maioria dos cientistas manteve a sua posição mesmo em situações evidencialmente desfavoráveis. De fato, poderíamos atribuir a esses cientistas uma simples postura dogmática e irracional, motivada por interesses pessoais e institucionais. Contudo, como observa Solomon (cf. Solomon, 2001, p. 86), diversos historiadores que se ocuparam da controvérsia da 
deriva continental, entre eles Frankel, chegaram à conclusão de que essa controvérsia envolvia apenas poucos fatores extracientíficos (não epistêmicos). Isso é importante, pois torna esse caso ainda mais apropriado para a discussão sobre a possibilidade de desacordo racional na ciência.

Como já destacado anteriormente, pretende-se argumentar que uma explicação da persistência do desacordo entre cientistas pode ser oferecida apelando para as diferentes perspectivas de acesso dos cientistas a determinada hipótese, diferença de acesso que é o resultado da divisão do trabalho cognitivo em diferentes especialidades. Essa maneira de ver o debate permite uma explicação da persistência do desacordo em termos cognitivos, sem recorrência a fatores não epistêmicos. Para tanto, irei me servir das análises de Andrew Lugg, Miriam Solomon e Naomi Oreskes, que se ocuparam da controvérsia da deriva continental e cujas abordagens enfatizam, entre outros aspectos, o papel das especialidades na escolha teórica.

Em seu artigo de 1978, Andrew Lugg visa explicar a existência de desacordos entre cientistas recorrendo à natureza de larga escala da ciência (large-scale nature of science) e, portanto, através das diferentes vias de acesso que os cientistas têm de determinada hipótese. Para compreender melhor a posição de Lugg, consideremos, a título de ilustração, a discussão de Lugg relativa à recepção da hipótese de Avogadro na comunidade de químicos do século xix (cf. Lugg, 1978). Segundo a hipótese de Avogadro, nas mesmas condições de temperatura e pressão, igual volume de todos os gases contém o mesmo número de moléculas. Esta hipótese foi largamente rejeitada na comunidade de químicos entre 1811 (quando Avogadro propôs a hipótese) e 1860 (quando Cannizaro propõe um forte argumento a seu favor) (cf. Lugg, 1978, p. 282). O ponto observado por Lugg é que aqueles poucos cientistas que aceitavam a hipótese tinham como principal ocupação o estudo da cristalografia, enquanto entre aqueles que rejeitavam a hipótese de Avogadro estavam praticamente todos os químicos orgânicos. Assim, para Lugg, o que explica o desacordo entre os cientistas relativo à hipótese de Avogadro não são fatores não epistêmicos, mas sim os diferentes pontos de partida e, portanto, as diferentes vias de acesso que cada lado tem da hipótese. Ele escreve que

O que eu quero argumentar é que esse desacordo surgiu como resultado de os participantes terem, por assim dizer, acesso diferente ao sistema de crença científica como um todo, em vez de terem sido influenciados por fatores não racionais ou extracientíficos. (...) Do ponto de vista do químico orgânico, havia pouco a favor da hipótese e muito contra ela (Lugg, 1978, p. 282).

Para Lugg, a diferença de acesso é uma consequência natural da natureza de larga escala da ciência. O ponto é que a ciência constitui um vasto sistema de ramificações no 
qual cientistas trabalham distribuídos em "nichos" e, embora determinado cientista possa adquirir um conhecimento profundo sobre determinada parte do sistema, seu conhecimento é apenas parcial no que concerne a outras áreas relacionadas. No curso normal das coisas, seu trabalho depende de resultados e métodos de outras áreas nas quais ele é menos familiarizado (cf. Lugg, 1980, p. 235).

Assim, o conhecimento científico é fruto da atividade comunitária de inúmeras mentes que trabalham distribuídas em diversas especialidades. Dessa divisão do trabalho cognitivo resulta que cada cientista possui seu acesso de entrada ao sistema, mas não possui um domínio completo do sistema. Desse modo, é a partir dessa característica estrutural da ciência que a resistência de cientistas frente às ideias rivais torna-se compreensível. O autor escreve:

Uma vez que a natureza de larga escala da ciência é apreciada, torna-se claro que a resistência não precisa ser nem irracional nem influenciada por fatores extracientíficos. Se, como parece indisputável, a ciência tal como a conhecemos é essencialmente um empreendimento em grande escala, cientistas podem diferir em sua escolha de teorias simplesmente porque as premissas em que baseiam seus argumentos variam com o seu acesso ao sistema total de crença científica (Lugg, 1980, p. 236).

Relativo ao debate da deriva continental, Lugg considera que a mesma diferença de acesso pode ser observada. Lugg cita o caso do geólogo russo Beloussov que apresentou forte resistência ao mobilismo, mesmo após a virada mobilista gerada pelos dados publicados pelos paleomagnetistas e geólogos marinhos (cf. Lugg, 1978, p. 285). Contudo, ao invés de ser considerado dogmático ou irracional, Beloussov, que tinha amplo conhecimento dos dados disponíveis, era respeitado por possuir uma abordagem sofisticada e racional, como afirma um editorial da Nature citado por Lugg. ${ }^{6}$ Novamente, a explicação para o desacordo de Beloussov residia numa diferença de acesso. Beloussouv era um geólogo ocupado com o estudo da geologia dos continentes, enquanto que os novos proponentes da deriva continental eram geólogos marinhos e paleomagnetistas que estudavam as cristas meso-oceânicas. De fato, Lugg observa que o papel das especialidades na escolha teórica já fora mencionado por Wegener que, por sua vez, reconhecia que uma teoria completamente distinta resultava, dependendo do ponto de vista com que o problema era abordado (cf. Lugg, 1978, p. 285). Assim, o ponto de Lugg é que, mesmo que os dados sejam todos publicamente conhecidos, a inter-

6 Em uma das passagens do editor da Nature lemos que "salvo uma observação ocasional de exasperação, todavia, a oposição de Beloussouv tem sido notável por sua abordagem objetiva e racional e, por essa razão, demanda uma resposta" (cf. Editorial, Nature Physical Science, 229, 18, 1971, p. 65). 
pretação desses dados pode diferir de acordo com a perspectiva de acesso do cientista a esses dados.

O papel da perspectiva de acesso também pode ser observado na situação inicial do debate. Miriam Solomon observa que os adeptos da nova teoria mobilista eram, em geral, cientistas que trabalhavam com materiais biológicos atuais e passados (fósseis) das costas da África e da América do Sul, enquanto que a voz fixista era proeminente entre geólogos que estudavam os materiais do hemisfério norte (cf. Solomon, 2001, p. 90). Novamente, isso não significa que os dados eram desconhecidos para os demais pesquisadores, a diferença residia na saliência desses dados, em como eles eram pesados e avaliados. Para Solomon e também Oreskes (cf. 1999) havia diferenças metodológicas importantes entre os proponentes da deriva continental e os fixistas da vertente permanentista que prevalecia extensamente nos Estados Unidos. Assim, cientistas dos Estados Unidos enfatizavam a primazia dos dados sobre a teoria, aderindo ao método indutivo. Isso os levava a favorecer o permanentismo, já que essa teoria, por excluir mudanças inobserváveis, era a posição que melhor se adequava ao método indutivo. Por sua vez, geólogos europeus tinham uma tradição especulativa que enfatizava a teorização, o que os levava a considerar mais seriamente tanto a deriva continental como o contracionismo. De fato, como observa Oreskes, a proposta de Wegener era explicitamente dedutiva, na qual um princípio básico foi usado para iluminar uma extensa gama de fenômenos (cf. Oreskes, 1999, p. 154).

Oreskes também argumenta que a forte tradição geofísica nos Estados Unidos explica em boa medida a rejeição da deriva continental por parte dos americanos. Os geofísicos enfatizavam a importância da experimentação e de análises matemáticas quantitativas. Assim, objetavam que a deriva continental não dispunha de uma formulação matemática que fornecesse resultados satisfatórios. De fato, esta também constituía uma das principais razões do geofísico britânico Harold Jeffreys, conhecido por suas habilidades matemáticas, para rejeitar a deriva continental. Por sua vez, mobilistas de áreas como a paleontologia e estratigrafia baseavam sua argumentação numa avaliação qualitativa da evidência fenomenológica disponível e, desse modo, em nítido contraste com a abordagem dos geofísicos. De fato, para mobilistas como Alexander du Toit, objeções ao mecanismo baseadas em argumentos matemáticos não deveriam ser consideradas decisivas, pois tais cálculos continham diversas pressuposições questionáveis (cf. Oreskes, 1999, p. 296).

Contudo, como visto, durante as décadas de 1950 e 1960 a situação será bem diferente, pois serão justamente as pesquisas de geofísicos em áreas como o paleomagnetismo que fornecerão dados quantitativos em favor do mobilismo. Em boa medida esses novos resultados explicam a aceitação gradual do mobilismo, pois eram fruto da instrumentação e satisfaziam os critérios de quantificação da comunidade geofísica 
americana. Assim, essa aceitação envolveu primeiramente paleomagnetistas e geólogos marinhos familiarizados com os novos resultados, enquanto os cientistas que continuavam a rejeitar o mobilismo estavam, essencialmente, ocupados em estudar a geologia dos continentes e exibiam menor familiaridade com as pesquisas em paleomagnetismo.

Isso permite observar que a perspectiva de acesso desempenhou papel importante na maneira como ocorreu a formação do consenso durante a controvérsia. De fato, Solomon (cf. Solomon, 2001, p. 102) observa que o consenso se formou a partir de cada especialidade, ou seja, boa parte dos especialistas se convencia apenas por observações relacionadas com a sua própria especialidade. Nesse sentido, a ordem da formação do consenso foi: paleomagnetistas, oceanógrafos, sismologistas, estratigrafistas e, por último, geólogos continentais. Assim, é a perspectiva de acesso que permite explicar por que no início de 1960 os paleomagnetistas estavam convencidos de que seus dados confirmavam o mobilismo, enquanto que os geólogos continentais continuavam "céticos" a esse respeito. O consenso apenas começou a emergir na medida em que os dados de cada especialidade confirmavam a hipótese da deriva continental. Mesmo com o sucesso da hipótese Vine-Matthews-Morley, que acabou por convencer praticamente todos os especialistas, a ordem em que se convenceram não foi independente da especialidade (cf. Solomon, 2001, p. 107).

Vemos, assim, que a divisão do trabalho cognitivo em diferentes especialidades desempenhou importante papel na escolha teórica no decorrer da controvérsia da deriva continental. Cientistas em diferentes especialidades diferiam na avaliação e interpretação dos mesmos dados. Como observado por Lugg na passagem citada acima, o ponto é que "cientistas podem diferir em sua escolha de teorias simplesmente porque as premissas em que baseiam seus argumentos variam com o seu acesso ao sistema total de crença científica" (Lugg, 1980, p. 236). Em outras palavras, Lugg está dizendo que, ao ocuparem diferentes nichos, cientistas apresentam diferenças no que concerne a informações de fundo (background information). ${ }^{7}$ Nesse sentido, a argumentação de Lugg vai ao encontro do que outros autores têm considerado como sendo as causas principais das controvérsias científicas, a saber, as diferenças em crenças ou suposições de fundo dos cientistas. Baltas (2000) considera que são as suposições de fundo (background assumptions) que permitem uma interpretação que conecta o sistema conceitual com a experiência, assinalando o papel das suposições de fundo na ocorrência de desacordos entre cientistas. Ele escreve:

${ }_{7}$ Dentre as informações relevantes não estão apenas os resultados experimentais e teóricos, mas também princípios metodológicos e metafísicos. Sobre o papel de tais princípios na atividade científica, cf. Mcmullin (1987) e Holton (1998). 
minha tese principal é a de que as controvérsias científicas ocorrem quando cientistas em desacordo não compartilham suposições de fundo. (...) ao perseguirem suas diferentes estratégias, os cientistas estão limitados por algo que eles não compartilham e que não estão em posição de revelar na mesa de discussão. O seu desacordo chega a uma controvérsia porque eles debatem uma questão sem tornar explícito os reais fatores, cuja existência silenciosa impede que todos recorram no mesmo momento, e da mesma forma, ao mesmo conjunto de critérios, normas, ou cânones (Baltas, 2000, p. 51-2).

Contudo, relativizar a escolha teórica a determinado conjunto de crenças de fundo pertencentes a determinado nicho teórico suscita a importante questão da objetividade. ${ }^{8}$ Nesse ponto, poder-se-ia objetar que a dependência da escolha teórica das crenças de fundo abre, novamente, espaço para a influência de fatores não epistêmicos como personalidade, educação etc. Isso porque tais crenças de fundo seriam função direta da subjetividade e personalidade individual de cada cientista. Segundo Lugg, tal objeção perde de vista o fato de que os cientistas não estão livres para criar os seus próprios nichos (cf. Lugg, 1980, p. 239). Pelo contrário, os cientistas devem desenvolver suas atividades dentro de nichos pré-existentes, nos quais dados observacionais, teorias e princípios metodológicos já estão bem estabelecidos. ${ }^{9}$ Embora um cientista possa escolher o nicho no qual pretende trabalhar, ele deve escolher um dos nichos já existentes. Assim, ao invés dos julgamentos de valor serem função direta da personalidade e educação do cientista, em Lugg a importância e peso relativo dos valores é função das informações e suposições de fundo do cientista, ou seja, nessa abordagem a avaliação teórica é relativa ao nicho em que cada cientista se encontra. ${ }^{10}$

Temos assim que reconhecer a natureza de larga escala da ciência e, consequentemente, a existência de diferentes perspectivas de acesso a determinada hipótese sugere que concepções de racionalidade mais permissivas do que aquela estabelecida pela tese da unicidade sejam admissíveis. Isso aponta para um primeiro passo em direção ao desacordo racional na ciência, restando agora considerar diretamente a problemática do desacordo tal como abordada na epistemologia contemporânea. Ou seja, a pergunta pela possibilidade do desacordo racional quando os pares ficam sabendo que estão discordando sobre determinada questão.

8 Utilizo aqui as expressões "crenças de fundo" e "suposições de fundo" de modo intercambiável.

9 Este ponto também é destacado por Thomas Kuhn. Em "Reflexões sobre meus críticos", ele afirma que "embora diferentes soluções tenham sido aceitas como válidas em diferentes ocasiões, não se pode forçar a natureza em um conjunto arbitrário de caixas conceituais" (2006, p. 197).

10 É importante destacar, como faz Lugg, que isso não significa um comprometimento com o relativismo. Embora a escolha teórica seja relativa a cada nicho, não há a priori nenhum impedimento para o estabelecimento de comunicação entre os nichos (cf. Lugg, 1980, p. 239). 


\section{Desagordo RAGional NA GiÊNGIA}

Como visto, a controvérsia da deriva continental exibe um considerável desacordo entre cientistas. Priorizei uma análise das causas dos desacordos que remetem a fatores epistêmicos e cognitivos, especialmente no que concerne ao papel desempenhado pelas crenças ou suposições de fundo na escolha teórica. Contudo, nesta discussão não consideramos a problemática do desacordo nos moldes em que é apresentada na epistemologia contemporânea. Assim, mesmo que os cientistas possam inferir racionalmente hipóteses incompatíveis a partir dos mesmos dados observacionais, a questão que se coloca agora é se os cientistas são racionais ao manterem a sua posição diante do desacordo com um colega igualmente competente que analisou os mesmos dados. Ou seja, se a suspensão de juízo não deveria ser a atitude racional, independentemente de ambos os lados do debate possuírem razões epistêmicas para a sua posição. ${ }^{11}$ De fato, tal posição repousa numa forte intuição, que remonta ao ceticismo antigo, de que o desacordo fornece evidência para possíveis erros que se possa ter cometido. Assim, em face da incapacidade de demonstrar que foi o nosso par que incorreu em erro, somos forçados a rever nossa posição sobre a matéria em disputa, pois permanecer na posição representaria um caso típico de dogmatismo.

Num primeiro momento, devemos concordar com o conformista de que os casos de dogmatismo devem ser evitados, contudo, como também argumentam autores não conformistas, é possível que, em muitos casos de desacordo, a resistência não precise receber o rótulo de dogmatismo ou irracionalidade. ${ }^{12}$ Esse "espírito" não conformista também está presente em Lugg (1980, p. 24.0) que destaca que a resistência frente ao desacordo não é, necessariamente, um problema, desde que ela não viole a virtude da mente aberta (open-minded). Seguindo Riggs, podemos definir a mente aberta como sendo uma atitude de segunda ordem para com as nossas crenças, ou seja, adotar uma atitude de mente aberta significa que reconhecemos a nossa falibilidade com respeito ao que cremos (cf. Riggs, 2010). De fato, por ser uma atitude de segunda ordem ela não é incompatível com a crença no primeiro nível, tudo o que é requerido é que se esteja disposto a considerar seriamente as objeções apresentadas por nossos pares. ${ }^{\mathbf{3}}$ Essa 11 De fato, a posição conformista nos remete à norma do "ceticismo organizado" constituinte do éthos científico na abordagem de Robert Merton (1968, p. 615). Contudo a argumentação que segue não é de todo incompatível com a norma mertoniana se esta, ao invés da suspensão de juízo, requerer apenas que os cientistas tenham uma atitude crítica e de mente aberta.

12 A posição não conformista sobre o desacordo é defendida, especialmente, por Kelly (2005, 2010), Sosa (2010), Lackey (2010) e Kvanvig (2011). Tais autores defendem uma posição pró-desacordo racional. Sobre os casos de dogmatismo kripkeano, cf. também Kelly (2008).

13 Enquanto a dúvida é, de fato, incompatível com a manutenção da crença em P, a atitude de mente aberta não significa o mesmo que a dúvida, tudo o que é exigido é que exista uma disposição para tomar a sério objeções contra P (cf. Riggs, 2010, p. 180). 
maneira de ver a questão sugere que um cientista que resiste ou permanece em sua posição não é dogmático quando ele está disposto a considerar seriamente as objeções do par epistêmico, bem como fornecer razões para sua própria posição. De fato, a persistência do desacordo pode ser até mesmo benéfica para o desenvolvimento das posições, na medida em que colabora para o estabelecimento de um criticismo mútuo e saudável entre teorias competidoras. ${ }^{\mathbf{4}}$

Isto nos conecta com outro aspecto que deve ser observado quando consideramos a problemática do desacordo na ciência, a saber, a natureza dinâmica das controvérsias científicas. As controvérsias científicas, inclusive a controvérsia da deriva continental, apresentam uma contínua troca de razões e argumentos. Uma controvérsia é um episódio dinâmico que envolve deliberação, questionamentos, investigação. Numa controvérsia desacordos são gerados, sustentados e resolvidos pela contínua troca de razões e argumentos (cf. Kelp \& Douven, 2011, p. 4). De fato, a análise que Frankel faz da controvérsia da deriva continental enfatiza, justamente, esse caráter dinâmico da controvérsia. Segundo o autor,

(1) proponentes de teorias competidoras tentam oferecer soluções para um conjunto comum de problemas que constituem o objeto da controvérsia; (2) proponentes de teorias competidoras tentam trazer dificuldades para as soluções dos seus oponentes; (3) essas soluções atacadas são defendidas contra as dificuldades suscitadas, alterando as soluções de modo a evitar as dificuldades ou mostrando que as dificuldades são infundadas. Às vezes a solução atacada é simplesmente substituída por uma nova solução que evita as dificuldades. (4) O término da controvérsia ocorre quando um lado desfruta de uma reconhecida vantagem em sua capacidade de responder as questões relevantes. À luz dos pontos (2) e (3), isso ocorre quando um dos lados desenvolve uma solução que não pode ser destruída por seus oponentes (Frankel, 1987, p. 203).

Assim, por exemplo, em (1) temos a alegação inicial de Wegener de que sua teoria fornecia explicações dos fenômenos (a)-(d). Em (2) temos tanto as objeções de fixistas contra Wegener, bem como as críticas de Wegener à solução fixista. Do lado fixista, temos a crítica feita pelo paleontólogo George Gaylord Simpson de que os mobilistas haviam sobre-estimado consideravelmente o número de casos legítimos

14. A defesa do desacordo racional feita neste trabalho de modo algum visa favorecer o desacordo em detrimento do consenso na ciência. De fato, é justamente após um processo de crítica, questionamento e debate que aquilo que chamamos de conhecimento científico envolve o consenso dos membros da comunidade científica sobre a legitimidade teórica e empírica de determinada teoria. Nesse sentido, ao falar em consenso sobre determinado tópico, anteriormente controverso, está se supondo que a controvérsia chegou ao seu término via resolução racional (cf. Mcmullin, 1987). 
de fósseis que apoiavam sua teoria, bem como a objeção do fixista Harold Jeffreys contra a analogia com icebergs, alegando que os continentes diferentemente dos icebergs se despedaçariam durante o deslocamento horizontal. Já do lado mobilista temos as críticas de Wegener e outros mobilistas à existência de pontes de terra, pois além de não existirem mecanismos conhecidos que explicassem o desaparecimento dessas pontes de terra no oceano, esse afundamento estaria em conflito com o princípio da isostasia. Em (3) temos as implementações das teorias por protagonistas como du Toit, Holmes e Hess do lado mobilista e Jeffreys, Simpson e Ewing do lado fixista. Finalmente, em (4) temos o esplêndido sucesso da hipótese Vine-Matthews-Morley que culminou com o término da controvérsia.

Desse modo, podemos perceber que, numa controvérsia, existe um processo dinâmico para o qual o debate contemporâneo sobre o desacordo não prestou a devida atenção. De fato, é válido notar que os conformistas dirigem seu veredicto sempre à situação estática, que envolve dois pares que compartilharam a mesma evidência e que se encontram numa situação de desacordo insolúvel. Ou seja, uma situação em que ambos os lados da disputa estão impedidos de buscar mais informações, seja via deliberação racional ou investigação empírica. Contudo, numa controvérsia, os cientistas dificilmente se encontram de mãos atadas. Nesse sentido, quando tomamos em consideração os casos de desacordo durante períodos de controvérsia científica, o modelo estático sugere uma simplificação inadequada que não capta o dinamismo das controvérsias. Isso sugere que existe uma diferença entre perguntar pela possibilidade do desacordo racional estático e a possibilidade do desacordo racional num episódio dinâmico que envolve argumentação e debate.

De fato, Kelp e Douven (2009) argumentaram que uma concepção dinâmica pode tornar o desacordo racional muito mais plausível do que no modelo estático enfatizado por Feldman. A proposta dos autores é particularmente útil para nossos propósitos e merece ser mencionada em maior detalhe. Os autores sugerem uma maneira de implementar a ideia recorrendo a uma estrutura de rounds que envolve a diferenciação entre dois tipos de rounds: deliberativo (deliberative) e revelador (disclosive). No primeiro round (deliberativo) cada agente avalia a evidência disponível e suas razões para crer. No segundo round (revelador) cada um expõe abertamente suas razões. Para os autores, a partir dessa estrutura dinâmica seria possível argumentar em defesa do desacordo racional. Eles escrevem:

Está longe de ser claro que, ao final de uma dada etapa deliberativa, os pares em desacordo devam, do ponto de vista epistêmico, suspender o juízo. Pelo contrário, intuitivamente, se está autorizado a manter a atitude opinativa desde que: 
$\left(\mathrm{S}_{1}\right)$ se encontre razões para resistir à argumentação do par em favor da própria conclusão, e/ou

(S2) se descubra nova evidência em apoio a nossa própria crença, e/ou

(S3) se é capaz de explicar como nosso par poderia ter-se envolvido em erro (Kelp

\& Douven, 2009, p. 4).

Contudo, os autores são explícitos em enfatizar a necessidade de o agente engajarse no debate com seu par. Ou seja, segundo os autores, a permissão para continuar a crer deve estar vinculada aos seguintes deveres:

(D1) O dever para com o nosso par de considerar os seus pontos de vista (por exemplo, em uma das formas descritas em ( $\left.\mathrm{S}_{1}\right)$-(S3) acima);

(D2) O dever de suspender o juízo, se ocorrer que não se pode cumprir adequadamente o dever estabelecido em (Dı) (Kelp \& Douven, 2009, p. 6).

Aparentemente, tal concepção permite conciliar de forma harmoniosa intuições pró e contra o desacordo racional. Isso porque durante a sucessão de rounds haveria espaço para o desacordo racional sem, contudo, ferir a intuição conformista, pois o motivo de cada lado engajar-se no debate é justamente o ideal conformista de atingir o consenso.

Assim, por exemplo, pode-se observar que a cláusula (Dı) capta justamente a atitude de tolerância e mente aberta necessária para evitar os casos flagrantes de dogmatismo que havíamos mencionado anteriormente. Pois adotar uma atitude de mente aberta significa que se está disposto a considerar seriamente as objeções do par, engajando-se no debate. Contudo, como já observado anteriormente, tomar a sério objeções contra suas crenças não significa que um agente possua dúvida suficiente para perder tais crenças. Tomar a sério objeções significa que ele reconhece que sempre existe a possibilidade de ter cometido um erro. Isso não precisa afetar decisivamente a sua convicção original, pois de outro modo o mero comprometimento com o falibilismo tornaria impossível manter qualquer crença (cf. Riggs, 2010, p. 180).

Contudo, é igualmente possível que, em determinados casos, a concepção dinâmica tenha como veredito a suspensão de juízo. Pois é possível que, ao final de um round deliberativo, um ou ambos os pares não consigam satisfazer as cláusulas $\left(\mathrm{S}_{1}\right)$ (S3) recomendadas por Kelp e Douven. No entanto, é também razoável supor que quando considerarmos áreas efervescentes, onde o debate está longe de chegar ao seu término e onde há um fluxo contínuo de novas informações, a pressão em direção à suspensão de juízo tende a diminuir. Assim, parece ser o caso que o desacordo racional 
é mais plausível dentro de uma concepção dinâmica, porque nessa concepção o agente não está impedido de fornecer razões adicionais, que ele "encontra" ao longo do debate, para manter a sua posição.

Com isso, concorda-se com autores não conformistas na rejeição de uma regra geral que dita o agnosticismo em casos de desacordos persistentes. A presente sugestão é de que, adotando o modelo dinâmico, podemos interpretar o significado epistêmico do desacordo como residindo, primariamente, numa atitude reflexiva, de reconhecimento da nossa falibilidade, que está expressa na virtude da mente aberta. É interessante notar que esta interpretação capta a intuição conformista de que o desacordo representa uma oportunidade de melhora epistêmica. Pois adotar uma atitude de mente aberta constitui um meio para eliminar erros e maus hábitos de pensamento, como vieses que se manifestam, especialmente, naquelas situações em que nossas crenças mais fundamentais são contestadas (cf. Riggs, 2010). De fato, assim como um agente de "mente fechada" (closed-mindedness) pode tomar como óbvias e universais suas próprias suposições, um cientista "tendencioso" pode tomar seu próprio nicho teórico, com o qual possui maior afinidade, como sendo a fonte de toda evidência relevante sobre a questão em disputa. Esse risco é amenizado se o cientista exibe e torna eficaz em sua vida cognitiva a virtude da mente aberta. Além de considerar seriamente as objeções do par, ele também estará considerando a evidência competidora proveniente de outros nichos teóricos com os quais possui menos afinidade. Assim, é a atitude de mente aberta que permite identificar e restringir a ação de vieses que podem favorecer dogmaticamente as suposições de seu nicho teórico. Nesse sentido, a atitude de mente aberta também permite captar a ideia de que os pares possam interagir construtivamente, gerando transformações em suas posições ao longo da controvérsia, respeitando a constatação histórica de que as controvérsias "evoluem” (cf. Kitcher, 2000, p. 22). Desse modo, além de captar o dinamismo das controvérsias científicas e respeitar intuições conformistas relevantes, o modelo proposto permite uma defesa do desacordo racional que respeita as peculiaridades de cada caso de desacordo e, desse modo, evita as consequências embaraçosas da posição conformista para a racionalidade dos cientistas em períodos de controvérsia científica.

\section{Conclusã̃o}

Este ensaio tratou da possibilidade do desacordo racional entre cientistas em períodos de controvérsia científica. No intuito de evitar as consequências indesejadas do agnosticismo conformista para a racionalidade dos cientistas em desacordo, como aqueles envolvidos na controvérsia da deriva continental, defendeu-se uma posição 
que respeita as intuições conformistas consideradas relevantes, mas que, ao mesmo tempo, permite um veredito não conformista em determinados casos de desacordo. Nesse sentido, dois elementos receberam destaque especial na defesa do desacordo racional na ciência, a saber, o papel da perspectiva de acesso e das crenças de fundo na escolha teórica e a natureza dinâmica das controvérsias científicas.

A abordagem proposta sugere que diferenças entre cientistas que remetem a diferentes perspectivas de acesso e, portanto, diferenças em crenças de fundo, permitem uma explicação do desacordo entre cientistas em termos racionais, sem recorrência a ação de fatores não epistêmicos. Assim, dentro da perspectiva falibilista, implícita neste trabalho, embora o desacordo indique que ao menos um dos pares esteja em erro, isso não significa, necessariamente, que algum cânone de racionalidade tenha sido violado. Por sua vez, a ênfase na natureza dinâmica das controvérsias científicas permitiu uma argumentação pró desacordo racional, mesmo quando cientistas passam a ter conhecimento de que estão protagonizando um desacordo com seu respectivo par epistêmico. Apelando para uma estrutura de rounds, proposta por Kelp e Douven, argumentou-se que cientistas em desacordo estão autorizados a manter a sua posição desde que considerem seriamente as objeções de seus pares e sejam capazes de fornecer razões epistêmicas para manter sua posição.

Assim, de acordo com a concepção defendida neste artigo, não existe uma razão a priori contra a possibilidade de manter a posição em face do desacordo. Ao invés de um princípio geral que dita o agnosticismo, o veredicto dependeria de aspectos contingentes característicos de cada caso. Dessa forma, antes de qualquer decisão sobre se o veredito de determinado caso de desacordo é conformista ou não conformista, a posição defendida sugere que o significado epistêmico do desacordo reside, primariamente, na virtude da mente aberta. Essa ênfase na virtude da mente aberta permitiu captar a intuição conformista de que o desacordo fornece evidência para possíveis erros que se possa ter cometido e, desse modo, passar a eliminar tais erros. Nesse sentido, concorda-se com os autores conformistas quando entendem que o desacordo representa oportunidade de melhora epistêmica, contudo, discorda-se deles quando defendem que, no processo de melhora epistêmica, a única opção disponível seja a suspensão de juízo. Dito de outra maneira, pares epistêmicos em desacordo não carregam, necessariamente, o ônus da irracionalidade.@

Alexandre Luis Junges Pontifícia Universidade Católica, Rio Grande do Sul, Brasil aljunges@gmail.com 


\title{
Rational disagreement and scientific controversy
}

\begin{abstract}
ABSTRAGT
Recent epistemological debate about what came to be called "the problem of rational disagreement" resumed the discussion, present among the ancient skeptics, on the epistemic significance of disagreement. Similar to the Pyrrhonian skeptic, some authors involved in the contemporary debate argued that in controversial contexts, where there is disagreement on some specific matter, the rational attitude of both sides of the debate is the suspension of judgment. For these authors, such a verdict should be extended to several fields of human knowledge, resulting in local skepticism regarding controversial topics. This article addresses this problematic in the scientific field. In several episodes of scientific controversy, scientists exhibit persistent disagreements where each side of the debate maintains his position in the face of disagreement. In this context, the question of the possibility of rational disagreement among scientists considered epistemic peers arises. From the structural and dynamic characteristics of science, it is argued that rational disagreement between scientists is possible. In other words, unlike the claims of contemporary authors, in the scientific context the epistemic significance of disagreement is not, necessarily, agnosticism.
\end{abstract}

KEYWORDS • Controversy. Disagreement. Evidence. Skepticism. Rationality. Justification. Epistemic peer.

\section{REFERÊNGIAS BIBLIOGRÁFIGAS}

Battas, A. Classifying scientific controversies. In: Machamer, P. et al. (Ed.) Scientific controversies: philosophical and historical perspectives. Oxford: Oxford University Press, 2000. p. 4,0-9.

Brown, J. Who rules in science: an opinionated guide to the wars. Cambridge: Harvard University Press, 2001.

Christensen, D. Epistemology of disagreement: the good news. Philosophical Review, 116, 2, p. 187-217, 2007 .

Disagreement, question-begging, and epistemic self-criticism. Philosopher's Imprint, 11, 6, p. 122, 2011.

Elga, A. Reflection and disagreement. Noûs, 41, 3, p. 478-502, 2007.

Engelhard Júnior, H. T. \& Caplan, A. L. (Ed.). Scientific controversies: case studies in the resolution and closure of disputes in science and technology. Cambridge: Cambridge University Press, 1987.

Feldman, R. Epistemological puzzles about disagreement. In: Hetherington, S. (Ed.). Epistemology futures. Oxford: Oxford University Press, 2006. p. 216-36.

. Reasonable religious disagreements. In: Antony, L. M. (Ed.).Philosophers without gods: meditations on atheism and the secular life. New York: Oxford University Press, 2007. p. 194-214.

Evidentialism, higher-order evidence, and disagreement. Episteme, 6, 3, p. 294-312, 2009.

Frankel, H. The continental drift debate. In: Engelhard Júnior, H. T. \& Caplan, A. L. (Ed.). Scientific controversies: case studies in the resolution and closure of disputes in science and technology. Cambridge: Cambridge University Press, 1987. p. 203-4.8.

Hоцтом, G. The advancement of science, and its burdens. Cambridge: Harvard University Press, 1998. 
Kelly, T. The epistemic significance of disagreement. In: Gendler, T. S. \& Hawthorne, J. (Ed.). Oxford studies in epistemology. New York: Oxford University Press, 2005. v. 1, p. 167-96.

Disagreement, dogmatism, and belief polarization. The Journal of Philosophy, 105, 10, p. 611-33, 2008.

. Peer disagreement and higher order evidence. In: Feldman, R. \& Warfield, T. (Ed.). Disagreement. New York: Oxford University Press, 2010. p. 111-74.

Kelp, C. \& Douven, I. Sustaining a rational disagreement. Conference of the European Philosophy of Science Association (Amsterdam, 21-24 October, 2009): EPSA 2009 Symposia. Disponível em: $<\mathrm{http}: / / \mathrm{philsci-}$ archive.pitt.edu/archive/oo005231/o1/SRD1.pdf $>$. Acesso em: jan. 2011.

Kitcher, P. Patterns of scientific controversies. In: Machamer, P. et al. (Ed.). Scientific controversies: philosophical and historical perspectives. Oxford: Oxford University Press, 2000. p. 21-39.

Kunn, T. Objectivity, value judgment and theory choice. In: __. The essential tension: selected estudies in the scientific tradition and change. Chicago: The University of Chicago Press, 1977. p. 320-39.

. O caminho desde a estrutura: ensaios filosóficos, 1970-1993, com uma entrevista autobiográfica. São Paulo: Editora Unesp, 2006.

Kvanvig, J. The rational significance of reflective ascent. In: Dougherty, T. (Ed.). Evidentialism and its discontents. Oxford: Oxford University Press, 2011. p. 34-54.

LACKEY, J. A justificationist view about disagreement's epistemic significance. In: Haddock, A.; MillaR, A. \& Pritchard, D. (Ed.). Social epistemology. Oxford: Oxford University, 2010. p. 298-325.

Lammenranta, M. The pyrrhonian problematic. In: Greco, J. (Ed.). The oxford handbook of skepticism. Oxford: Oxford University Press, 2011. p. 9-33.

Leinz, V. \& Amaral, S. do. Geologia geral. São Paulo: Nacional, 2001.

LugG, A. Disagreement in science. Journal for General Philosophy of Science, 9, 2, p. 276-92, $197^{8}$. Theory choice and resistance to change. Philosophy of Science, 47, 2, p. 227-4,3, 1980.

Maghamer, P.; Pera, M. \& Baltas, A. (Ed.). Scientific controversies: philosophical and historical perspectives. Oxford: Oxford University Press, 2000.

Mcmullin, E. Values in science. Proceedings in the Biennial Metting of the Philosophy of Science Association. East Lansing, 1982. v. 2, p. 3-28.

The rational and the social in the history of science. In: BRown, J. R. (Ed.). Scientific rationality: the sociological turn. Dordrecht: Reidel, 1984. p. 127-64.

Scientific controversies and its termination. In: Engelhard Júnior, H. T.; Caplan, A. L. (Ed.). Scientific controversies: case studies in the resolution and closure of disputes in science and technology. Cambridge: Cambridge University Press, 1987. p. 49-91.

Merton, R. K. Social theory and social structure. New York: The Free Press, 1968.

Oreskes, N. The rejection of continental drift: theory and method in American earth science. New York: Oxford University Press, 1999.

RigGs, W. Open-Mindedness. Metaphilosophy, 41, 1-2, p. 172-88, 2010.

Solomon, M. Scientific rationality and human reasoning. Philosophy of Science, 59, 3, p. 439-55, 1992. Social empiricism. Massachussetts: The MIT Press, 2001.

Sosa, E. Epistemology of disagreement. In: Haddock, A.; Millar, A. \& Pritchard, D. (Ed.). Social epistemology. Oxford : Oxford University, 2010. p. 278-97. 